\title{
A inspeção predial no apoio as ações judiciais: análise das condições de segurança estrutural de uma residência unifamiliar em Recife/PE.
}

\author{
N. C. M S DA Silva ${ }^{1 *}$, R. G. D. Freire ${ }^{2}$ \\ ninaceleste184@.gmail.com \\ ${ }^{1}$ Depart ${ }^{\circ}$ de Engenharia Civil, Centro Universitário da Vitória de Santo Antão (UNIVISA), Pernambuco Brasil \\ ${ }^{2}$ Depart $^{\circ}$ de Engenharia Civil, Centro Universitário da Vitória de Santo Antão (UNIVISA), Pernambuco Brasil.
}

\begin{abstract}
RESUMO
Este trabalho descreve problemas construtivos levantados em edificação situada em Recife/PE baseado na NBR 16.747:2020 e na Norma de Inspeção Predial Nacional. O objetivo principal é apresentar o resultado de laudo técnico sobre as condições de habitabilidade e segurança estrutural da construção. O método para inspeção foi vistoria visual (sensorial), anamnese e observação dos sistemas construtivos executados. A partir das avaliações dos processos construtivos executados sem a observância das normas para obras de concreto armado; das manifestações patológicas provenientes da ação vibracional cíclica do local devido à existência de uma estação de metrô nas proximidades do imóvel, qualificou-se a inspeção como Nível 1 e o grau de risco Mínimo, mas recomenda-se o monitoramento regular para acompanhar evolução de danos futuros.
\end{abstract}

Palavras-chave: inspeção predial; vistoria, laudo; manifestações patológicas; durabilidade.

Este trabajo describe los problemas de construcción planteados en un edificio en Recife/PE con base en NBR 16747:2020 y la Norma Nacional de Inspección de Edificios. El objetivo es presentar el resultado de un informe técnico sobre las condiciones de habitabilidad y seguridad estructural de la construcción. El método fue inspección visual, anamnesis y observación de los sistemas 
realizados. A partir de las evaluaciones de los procesos constructivos sin el cumplimiento de las normas para obras de hormigón armado; de las manifestaciones patológicas derivadas de la acción vibracional cíclica del sitio debido a la existencia de una estación de metro en las inmediaciones de la propiedad, la inspección como nivel 1 y el grado de riesgo mínimo fueron calificados.

Palabras clave: inspección de edificios; reporte de encuesta; manifestaciones patológicas; durabilidad.

This work describes construction problems raised in a building in Recife/PE based on NBR 16747:2020 and the National Building Inspection Standard. The main objective is to present the result of a technical report on the conditions of habitability and structural safety of the construction. The method for inspection was visual inspection, anamnesis and observation of the construction systems performed. From the evaluations of the construction processes carried out without 
compliance with the standards for reinforced concrete works; of the pathological manifestations arising from the cyclic vibrational action of the site due to the existence of a subway station in the vicinity of the property, inspection was classified as Level 1 and the minimum risk degree, but regular monitoring is recommended.

Keywords: building inspection; survey, report; pathological manifestations; durability.

\section{INTRODUÇÃO}

Uma situação comum nos bairros de moradia popular são as contendas entre vizinhos durante o período de construção e/ou reformas das moradias, que muitas vezes resulta em ações judiciais. Nesses casos, uma ou ambas as partes, recorrem a profissionais especializados para dirimir 
questões decorrentes de incômodos acústicos ou até mesmo os riscos quanto à segurança estrutural (patrimonial).

A realização de reformas ou intervenções em edificações com alvenaria autoportante ou alvenaria estrutural, como também para estruturas mistas com a integração de pilares, vigas e lajes em concreto armado e as alvenarias de blocos cerâmicos, exige permanente monitoramento dos processos construtivos e atendimento as prescrições normativas referentes a tipologia construtiva escolhida, bem como uma análise sobre as interferências na vizinhança de forma constante.

O grau de risco se estabelece em função das anomalias ou falhas detectadas, as quais devem ser sempre fundamentadas, conforme os limites e os níveis da Inspeção Predial, e as condições de risco oferecido aos usuários, ao meio ambiente e ao patrimônio, de acordo com a Norma de Inspeção Predial Nacional/IBAPE, 2012.

Apesar das Leis relacionadas ao direito de vizinhança ou direitos do consumidor apontados no Código Civil (Lei 10.406/2002) e no Código de Direito do Consumidor (Lei 8.078/1990), muitas vezes se faz necessário a averiguação in loco por um observador externo as partes, que através a avaliação predial contribuirá para a resolução de problemas.

Nesse sentido a Norma Técnica (NBR 16.747:2020 - Inspeção Predial - Diretrizes, conceitos, terminologia e procedimento) estabelece que a inspeção predial tem por finalidade verificar as condições técnicas da edificação, dos sistemas e dos subsistemas construtivos, de forma predominantemente sensorial para caracterizar, quantificar e qualificar as manifestações patológicas detectadas. A partir da inspeção predial será elaborado um Laudo Técnico, para tal será realizada uma vistoria técnica com observações visuais da construção permitindo um diagnóstico e posteriormente elaboração de um prognóstico sugerindo terapias preventivas e/ou corretivas.

O principal objetivo deste artigo é apresentar uma inspeção predial e laudo técnico sobre as condições de habitabilidade e segurança estrutural de uma residência situada a Rua Francisco Porfírio $\mathrm{n}^{\circ} 188$ Afogados, Recife/PE, a partir de uma demanda judicial, descrevendo dados e informações, sobre o imóvel.

O imóvel em análise está a cerca de 100 m de distância de uma Estação do metrô de superfície do Recife. Por conseguinte, foi necessário realizar uma monitoração da constância vibracional no local a fim de se verificar se há contribuição do ciclo de trepidações e frenagem dos trens, no surgimento de manifestações patológicas ou danos efetivos nas edificações estudadas.

A impretaçao de ação judicial visa propiciar mais segurança para as partes, vizinhos e proprietários, uma vez que os resultados do laudo apontarão os problemas patológicos provenientes da execução das etapas construtivas sem a obediência às prescrições normativas dos sistemas construtivos e de instalações prediais que fundamentarão decisoes futuras.

\section{MÉTODOS AVALIATIVOS}

Inicialmente foi realizada uma anamnese com o Engenheiro Civil responsável pela execução da obra com a finalidade de compreender a necessidade de elaboração do laudo, a real motivação, a fim de estabelecer o planejamento da inspeção e, ao mesmo tempo atender à solicitação judicial para que fosse possível apoiar a decisão do Juiz de Direito. O contratante discriminou da seguinte forma os objetivos do laudo: o "Laudo será apresentado para os proprietários e vizinhos a fim de fornecer mais segurança para ambos em relação à estrutura do imóvel”. Neste contexto é que foi realizada a vistoria técnica e a elaboração do laudo.

\subsection{Método}

Para elaboração do laudo técnico proveniente da inspeção predial foi aplicado a seguinte sequência de trabalho: 
a. Realização da vistoria presencial sensorial (visual) na residência para inspeção da estrutura instalada em todos os ambientes da edificação (pavimento térreo, primeiro e segundo andar);

b. Abertura em vala na base de um dos pilares (P2) para observação das características das fundações;

c. Realização de levantamento dimensional das peças estruturais como pilares e vigas da superestrutura do imóvel;

d. Escarificação de trechos da laje de piso do $1^{\circ}$ pavimento (terraço) foram escarificados para confirmação de aplicação de armadura (tela) da laje; averiguação de revestimento em gesso (teto do térreo/sala) para observação direção de aplicação da laje sobre vigas e pilares;

e. Realização de levantamento superestrutura de reservatório elevado construído de forma independente a residência;

f. Foram realizadas inspeções visuais em duas edificações vizinhas;

g. Realização de retro análise computacional sobre as condições estruturais do imóvel, a partir do levantamento das dimensões das peças estruturais e das características do concreto utilizado, com base em informações coletadas;

h. Realização de análise das condições de proteção e segurança para serviços em altura, bem como dos serviços que ainda serão realizados nas áreas confrontantes com a vizinhança;

i. Verificação da influência de condição sismológica devido à proximidade da edificação a uma estação do metrô de superfície do Recife.

\subsection{Modelagem Computacional}

Para analisar a segurança estrutural da edificação foi realizada uma modelagem computacional através do programa CAD TQS Unipro12 Versão 22, para tanto foram criados dois modelos. As estruturas foram representadas por elementos de barras, com as propriedades geométricas e mecânicas equivalentes à peça da estrutura.

O primeiro modelo corresponde ao reservatório elevado (piscina), constituído por um conjunto rígido de pilares e vigas com 7,0 $\mathrm{m}$ de altura e caixa com laje pré-moldada de fundo e parede em alvenaria de blocos cerâmicos. O segundo um dos panos do piso ( $1^{\mathrm{o}}$ pavimento) que apresentava uma laje com espessura insuficiente diante do vão entre os apoios.

Em ambos os modelos, as lajes foram analisadas por meio pela analogia de grelha. Neste tipo de modelagem o meio contínuo é dividido em faixas onde cada uma dessas partes são discretizadas por uma barra que guarda as propriedades mecânicas e geométricas da faixa que representa, assim, é como recebe a carga desse trecho, (Campani, 2011). A criação da grelha é feita de maneira automatizada pelo programa computacional, a partir de configurações pré-determinadas pelo usuário e as características fornecidas na criação do modelo.

A modelagem das grelhas tem-se a partir das características relacionadas, levando em conta a estrutura analisada, (Campani, 2011):

$\checkmark$ Geração de barras com seção "T" para as lajes nervuradas;

$\checkmark$ Espaçamento entre barras (Largura das faixas) 0,35 metros;

$\checkmark$ O efeito de torção nas barras foi considerado no dimensionamento através da criação de uma envoltória que leva em conta a ação simultânea desse esforço com os momentos fletores;

$\checkmark$ O efeito da deformação lenta do concreto foi considerado de maneira simplificada por meio da multiplicação dos deslocamentos elásticos por 2,5;

$\checkmark$ O efeito da planificação nos apoios da laje foi levado em conta por meio do uso de uma rigidez equivalente a $85 \%$ a do engaste perfeito; 
Com o processamento do modelo, se obteve os esforços seccionais e deslocamentos em toda a estrutura. Esses dados são utilizados em sub-rotinas de verificação e dimensionamento que geram os detalhes de projeto e relatórios referentes a cada análise. No caso apresentado neste trabalho os relatórios foram utilizados para avaliar as inconsistências entre a execução da obra e as prescrições normativas. De maneira análoga às plantas de armadura geradas pelo programa serviram de parâmetro de avaliação da armadura existente no local. Com o suporte do recurso computacional foi possível dar precisão a verificação da estrutura e celeridade no apontamento dos itens em desacordo com as referências normativas.

\subsection{Interferência das vibrações produzidas pelo sistema de trens urbanos local.}

Os efeitos provocados pelas vibrações desencadeadas do sistema férreo existente nas proximidades das construções, pode ser avaliado a partir de três condicionantes. Esses elementos condicionantes são "pela fonte, pelo trajeto e pelo receptor" (Chaves, 2012). No caso da vibração induzida por trens, o trajeto para atingir o receptor pode se dar pelo solo e pelo ar", conforme indicado na Figura 1.

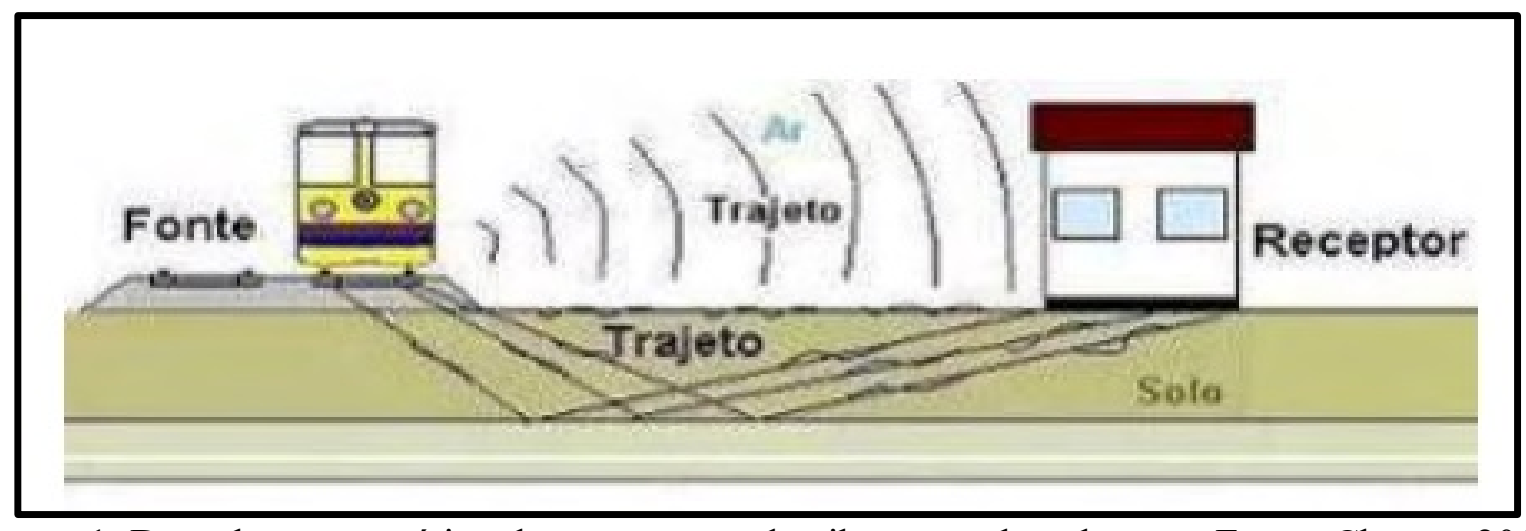

Figura 1: Desenho esquemático da propagação de vibração pelo solo e ar. Fonte: Chaves, 2012.

A faixa de domínio definida para ferrovias no Brasil é estabelecida pelo Decreto Federal $n^{\circ} 7.929$ de 18/02/2013 no Art. $1^{\circ} \S 2^{\circ}$. Assim, se verifica que faixa de domínio é a porção de terreno com largura mínima de quinze metros $15,0 \mathrm{~m}$ de cada lado do eixo da via férrea. Essa distância entre a linha férrea e as habitações com baixa qualidade construtiva ou com fundações implantadas em solos pouco resistentes aos impactos cíclicos que são gerados da constante ação vibratória de uma linha férrea ativa, podem gerar danos severos e constantes as construções. (Chaves, 2012).

No local da vistoria foi constatado que as construções existentes no bairro foram construídas antes da implantação da linha férrea do metrô de superfície do Recife, o qual foi construído na década de 1980, e as edificações datam das décadas de 1960 a 1970, ou seja, a instalação do bairro ocorreu antes da linha férrea. Assim, nenhuma dessas habitações foram projetadas ou construídas com vistas a suportar uma constante e cíclica condição de altas vibrações o que, consequentemente, ao longo do tempo, fez surgir manifestações patológicas que se refletem até hoje. No caso da construção tema deste trabalho, não foi diferente, como também das construções vizinhas examinadas.

\section{RESULTADOS}

As considerações e recomendações que foram expressas no laudo não são projetos executivos de qualquer natureza, principalmente por não ser esse o objetivo de um Laudo Técnico. No entanto, é permitido, que sejam emitidas recomendações das ações necessárias para restaurar ou preservar o 
desempenho dos sistemas, subsistemas e elementos construtivos da edificação. Assim, as avaliações descritas propõem algumas recomendações que posteriormente devem ser executadas.

\subsection{Avaliação das fundações: foi realizada abertura de vala de fundação sob o pilar 2 (P2).} Foi aberta uma vala com aproximadamente $1,0 \mathrm{~m} \times 1,0 \mathrm{~m}, 1,20 \mathrm{~m}$ (largura $\mathrm{x}$ comprimento $\mathrm{x}$ profundidade) para observação do tipo de fundação implantada na base do pilar. Verificou-se que $50 \mathrm{~cm}$, a partir da base do pilar, foi encontrado um alargamento executado em concreto, com a presença de aço, mas sem as características ou posicionamento das armaduras para construção de sapatas, blocos ou vigas baldrames.

A NBR 6122:2012 - Projeto e execução de fundações, define que as cargas de toda edificação devem ser distribuídas e transmitida ao terreno através das fundações. A ausência ou mau dimensionamento da infraestrutura, sejam rasas ou profundas, podem acarretar, imediatamente ou ao longo do tempo, danos irreversíveis a estabilidade e habitabilidade da construção. Por conseguinte, e levando em consideração os aspectos práticos utilizados para execução de muitas construções, foi indicado a elaboração de projeto de reforço de fundação com a implantação de sapatas isoladas sobre os pilares com as mesmas configurações encontradas no P2.

\subsection{Avaliação da superestrutura: levantamento dimensional dos elementos estruturais como pilares, vijas, lajes e escadas nos pavimentos térreo e superiores $\left(1^{\circ}\right.$ e $\left.2^{\circ}\right)$.}

Foram identificados pilares que não atendem as recomendações prescritas pela NBR ABNT 6118:2014 no item 18.4.2.1, conforme apresentado na Tabela 1, que define o diâmetro mínimo das armaduras longitudinais empregadas nos pilares deve ser de 10 milímetros e 5 milímetros para as armaduras transversais (estribos), desse modo se recomenda a execução de reforço estrutural precedido de Projeto Específico de reforço estrutural, devendo conter inclusive modo executivo da recuperação.

Tabela 1: Dimensões dos pilares da estrutura do imóvel

\begin{tabular}{c|c|c|c}
\hline \multirow{2}{*}{$\begin{array}{c}\text { Numeração } \\
\text { do pilar }\end{array}$} & \multicolumn{2}{|c|}{ Dimensões (cm) } & $\begin{array}{c}\text { Área do pilar } \\
\left(\mathrm{m}^{2}\right)\end{array}$ \\
\cline { 2 - 4 } & Largura & Espessura & 300 \\
\hline P1 & 30 & 10 & 675 \\
\hline P2 & 45 & 15 & 200 \\
\hline P3 = P8 & $20^{*}$ & 10 & 1125 \\
\hline P4 & 45 & 25 & 375 \\
\hline P5 & 25 & 15 & 450 \\
\hline P6 & 30 & 15 & 675 \\
\hline P7 & 45 & 15 &
\end{tabular}

Fonte: Os autores.

A fim de se obter mais dados sobre o comportamento da estrutura, sugeriu-se adoção de um sistema de monitoramento de indícios de danos, o que se reflete na implantação selos que mostrem fissuramento das paredes, futuramente, ou de qualquer outro elemento construtivo. Como surgimento de sinais de movimentação da estrutura, como o aparecimento de trincas ou fissuras. Estes indicadores são parâmetros para determinar o mau funcionamento do sistema como um todo. Neste sentido, a regularidade, pelo menos semestral do monitoramento, contribuirá para acompanhamento de uma possível evolução para danos estruturais.

É necessário que se acrescente que mesmo que as condições atuais da edificação não apresentem fortes indícios de vícios construtivos relacionados aplicação de cargas uniformes e concentradas, 
não previstas, o método construtivo determina a probabilidade do surgimento de manifestações a curto ou médio prazo. Por isso, foi recomendado o monitoramento, que deve ser acompanhado por profissional habilitado pelo sistema CONFEA/CREA.

\subsection{Avaliação da laje do primeiro piso - laje pré-fabricada}

A fim de melhorar a condição de estabilidade da referida laje, sem que seja necessário promover ação demolitória ou de remoção da peça estrutural, e visando a segurança da edificação. Foi recomendada a instalação de apoios intermediários com auxílio de vigas metálicas do tipo Perfil H - W200x19,3 ou por perfil similar com dimensões geométricas equivalentes ou superior. Esses materiais foram definidos a partir da necessidade de reforço estrutural, mas também considerando a disponibilidade das peças no mercado. A Tabela 2 mostra as especificações coletadas da laje do primeiro piso.

Tabela 2 - Dados da Laje Treliçada (primeiro piso)

\begin{tabular}{l|c}
\hline \multicolumn{2}{c}{ Dimensão da peça Estrutural } \\
\hline Largura da treliça (Nervura) & $12 \mathrm{~cm}$ \\
\hline Altura do enchimento & $8 \mathrm{~cm}$ \\
\hline Altura da capa de concreto & $4 \mathrm{~cm}$ \\
\hline Altura total da laje & $12 \mathrm{~cm}$ \\
\hline concreto & Classe C25 \\
\hline Aço & CA-50 \\
\hline
\end{tabular}

Fonte: Os autores.

A laje estudada, representada pela Figura 2, incorpora a estrutura as vigas metálicas, com o objetivo de reduzir sensivelmente a deformação da laje. Além disso, com esta intervenção, será dispensado o uso de armaduras de compressão e cisalhamento nas nervuras. A Figura 3, mostra uma planta geral da referida laje, incluindo o reforço proposto. Para instalação das peças indicadas devem ser tomadas todas as medidas necessárias para a solidarização com a estrutura existente.

Figura 2 - Distribuição de deformação da laje, com acréscimo de vigas metálicas. Fonte: Imagem do Software TQS. 


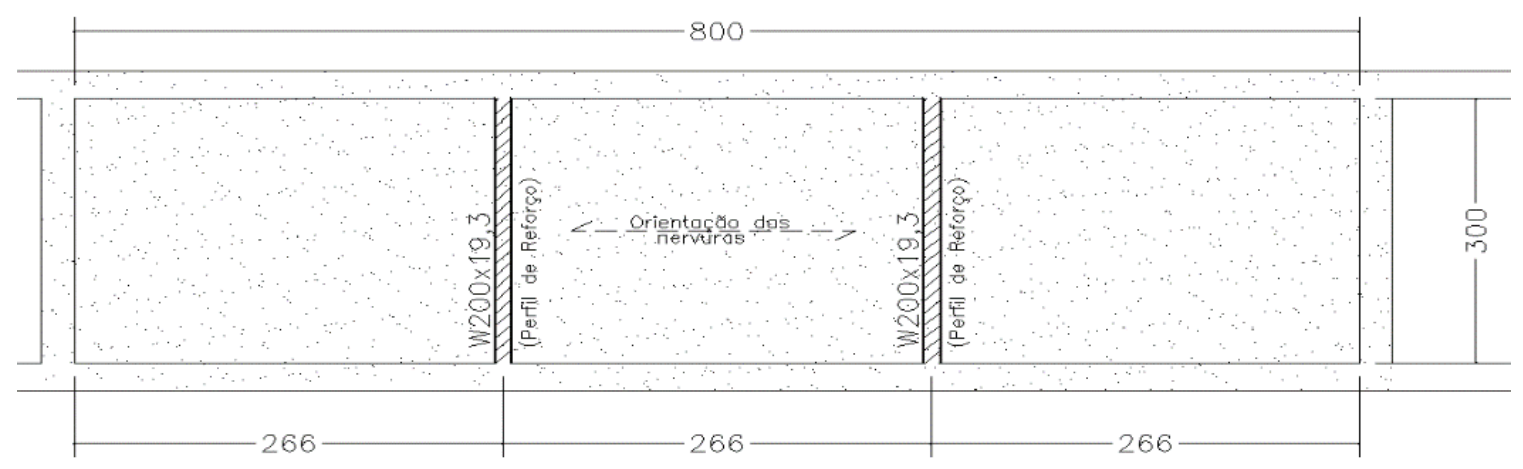

Figura 3 - Vista geral do reforço proposto. Fonte: Imagem do Software TQS.

\subsection{Avaliação de estrutura elevada para implantação de reservatório elevado - trecho independente da residência}

Para esse sistema, caracterizado como independente da estrutura da residência, se faz necessário proceder a correção da deformação apresentada na laje. Neste sentido, foi sugerido que, em ocorrendo a elaboração de Projeto estrutural de reforço, seja incluída a solução para a situação apresentada. Vale ressaltar que a laje em questão está situada a pelo menos 7,0m de altura em um ambiente aberto, para o qual há apenas a previsão da implantação de guarda corpo de vidro em todo o perímetro. A estrutura que suporta o reservatório elevado (piscina), se caracteriza por uma laje no topo dos pilares com dimensões de 300 x 250 centímetros, apoiadas sobre quatro vigas (em três níveis) e quatro pilares.

A vista geral do modelo computacional criado para auxiliar nas verificações da referida estrutura está apresentado na Figura 4. As características utilizadas para análise da laje, como dimensões e materiais foram as mesmas utilizadas e apresentadas nos itens anteriores. Após análise se verifica que os pilares atendem as características geométricas definidas pela NBR 6118:2014. Entretanto, os dados até então disponíveis não permite uma avaliação sobre o atendimento das quantidades mínimas de armadura, conforme também especifica a norma. A Tabela 3 apresenta os dados geométricos levantados durante visita ao local. Em relação às vigas da estrutura, foi observada uma seção com largura de 10 centímetros o que diverge das prescrições normativas indicadas nas alíneas a e b do item 13.2.2 da NBR ABNT 6118:2014.

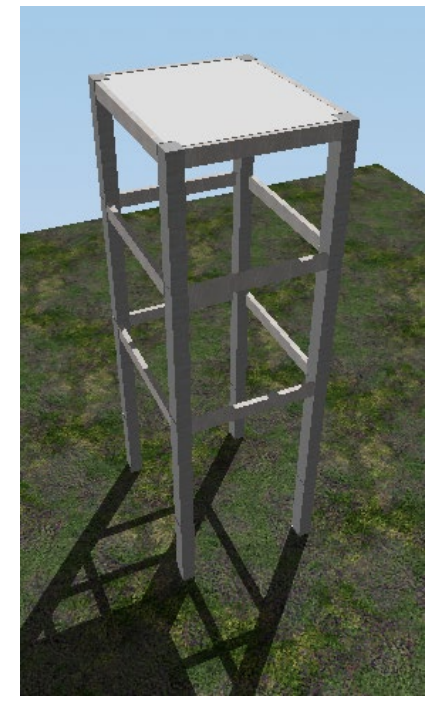

Figura 4 - Vista geral do modelo computacional da estrutura. Fonte: Imagem do Software TQS. 
Quanto a laje construída sobre essa estrutura elevada de pilares e vigas, há uma deformação de 2,60 centímetros, este valor excede os limites apontados na tabela 13.3 da NBR ABNT 6118:2014. Neste quesito, sobre a laje, é importante considerar a possibilidade de reforço estrutural, uma vez que, se para as condições mínimas, ou seja, ainda sem a carga acidental, já existe uma deformação não prevista, é possível que quando aplicadas as cargas para a estrutura como água, talvez pessoas, a deformação possa chegar a um estado limite ainda mais crítico.

Tabela 3: Dimensões dos pilares da estrutura do reservatório elevado.

\begin{tabular}{c|c|c}
\hline \multirow{2}{*}{$\begin{array}{c}\text { Numeração do } \\
\text { pilar }\end{array}$} & \multicolumn{2}{|c}{ Dimensões (cm) } \\
\cline { 2 - 3 } & Largura & Espessura \\
\hline P1 & 30 & 25 \\
\hline P2 & 30 & 25 \\
\hline P3 & 30 & 25 \\
\hline P4 & 30 & 25 \\
\hline
\end{tabular}

Fonte: Os autores.

\subsection{Avaliação das condições de trabalho em altura.}

A elaboração deste item tem por principal finalidade melhorar as condições executivas desenvolvidas na obra, bem como melhorar a relação com a vizinhança garantindo segurança aos passantes ou transeuntes no entorno da obra, de acordo com o que recomenda a NR1 8 . no item 18.9.1.

Assim, foi recomenda a instalação de alguns equipamentos de proteção coletiva (EPC):

$\checkmark$ Instalação de guarda corpo nas áreas de coberta em vãos livres;

$\checkmark$ Instalação de plataforma de proteção (bandeja de proteção), em especial, para os serviços realizados nas áreas que confrontam com as casas vizinhas;

$\checkmark$ Instalação de redes de segurança nas áreas que confrontam com as casas vizinhas;

Outros equipamentos de proteção individual devem ser adotados a fim de se evitar a ocorrência de acidentes no desenvolvimento da obra.

\subsection{Verificação das condições das edificações vizinhas}

\subsubsection{Casa vizinha $1-n^{0} 188$}

A vistoria nesta residência foi conduzida pela própria moradora. A mesma relatou, de forma breve, todas as ocorrências vivenciadas desde o início da reforma.

$\mathrm{Na}$ vistoria foram constatados alguns problemas patológicos tais como:

$\checkmark$ pontos de infiltração ascendente na parede divisória entre os imóveis;

$\checkmark$ infiltrações no teto da parede divisória, como também danos em outros pontos do teto em gesso, sal, quartos e cozinha, Figuras 5 e 6;

$\checkmark$ danos no telhamento da casa com várias telhas quebradas ou danificadas.

Foram ainda constatados danos como fissuras nas paredes, tratamento corretivo realizado, sendo as fissuras proveniente de permanente vibração que ocorre nas proximidades devido a existência de linha férrea. 


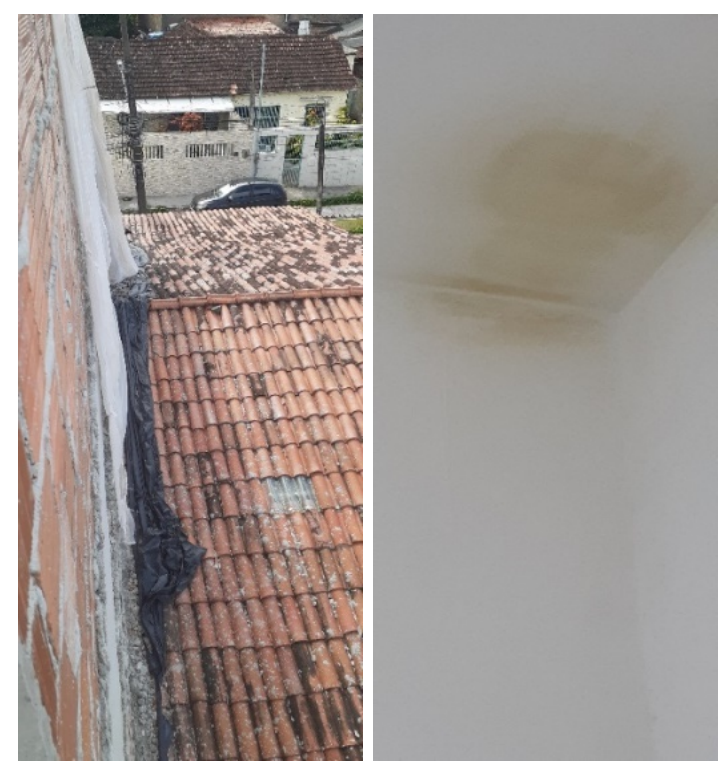

Figuras 5 e 6: Infiltrações no teto da parede divisória entre os imóveis. Fonte: Os autores.

\subsubsection{Casa vizinha $2-n^{0} 183$}

Neste imóvel não foram identificados, na data da vistoria, nenhum dano a estrutura ou outra parte do sistema construtivo que fosse atribuída a obra de reforma. Entretanto, foi relatado pela moradora sobre o desprendimento de materiais construtivos, devido ao andamento da obra. Não obstante as observações descritas pela habitante, foi possível constatar a não a instalação de dispositivos de proteção e segurança para trabalhos em altura, como o uso de tela de proteção, bandejas ou andaimes facheiros, conforme apresentado nas Figuras 7 e 8.
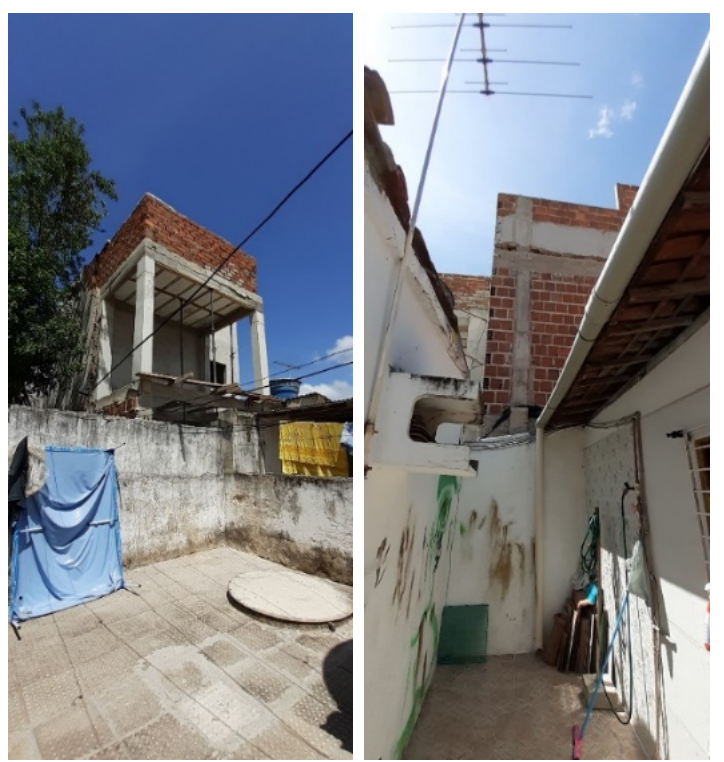

Figuras 7 e 8: Visão externa do reservatório elevado sem proteção, confrontando com dois imóveis. Fonte: Os autores.

\subsection{Efeitos das vibrações cíclicas e constantes nos imóveis devido à proximidade a uma estação de metrô.}

Foram observadas diversas fissuras nas casas da vizinhança em que foi realizada vistoria. Alguns desses danos foram identificados na base das paredes, em especial aquelas que ainda restam da construção originária, e em outros pontos na parte superior das paredes. Por ser uma região onde a 
idade de construção dos imóveis remonta pelo menos 40 anos e a implantação da rede ferroviária do metrô a cerca de 30 anos, há um intervalo de tempo que permite ao avaliador supor que as fundações ou superestrutura dos imóveis próximos as estações de metrô não tenham sido projetadas ou construídas levando em conta essa condição de vibrações constantes.

O imóvel vistoriado está distante da linha férrea cerca de $68,0 \mathrm{~m}$, conforme imagem da Figura 9 , indicando que está fora dos limites de faixa de domínio. Entretanto, foi um relato contundente dos moradores em ocorrer de maneira periódica o fissuramento das paredes.

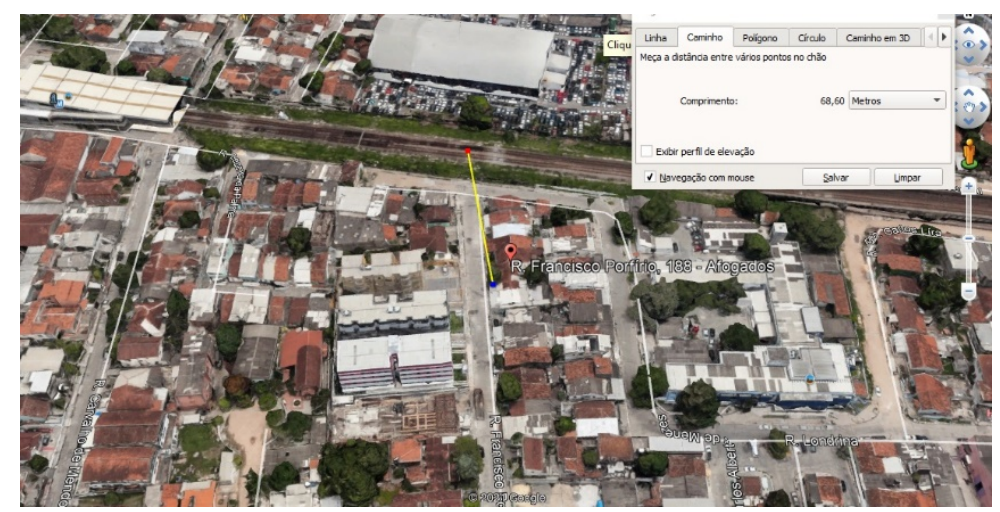

Figura 9: Imagem de satélite indicando a distância estimada entre o imóvel e a linha férrea. Fonte: Google Earth.

\section{CONCLUSÕES}

A partir dos resultados obtidos, decorrente das avaliações, foi possível qualificar a inspeção como de Nível 1 e o grau de risco como Mínimo. Essa classificação é apropriada para edificações com planos de manutenção muito simples ou inexistentes. A inspeção permitiu obter informações sobre as condições das fundações, das peças estruturais como pilares e vigas, como também do processo construtivo das lajes e das vedações verticais externas e internas.

Destaca-se que todas as condições construtivas devem observar o cumprimento das normas técnicas vigentes. Ressaltando, inclusive, a importância da observância das condições de segurança do trabalho necessárias, item também destacado na inspeção.

Dois importantes aspectos são identificados neste estudo: o primeiro se refere a importância do planejamento das etapas construtivas visando a gestão e controle de todo processo construtivo, desde a fase de elaboração de projetos, aquisição e controle do uso de materiais, da contratação de mão de obra qualificada, como também da gestão e controle do cronograma físio-financeiro; o segundo é que, para os casos de reforma, torna-se ainda mais importante a gestão geral do processo. Pode-se concluir, também, que a gestão na relação vicinal, ou com os intervenientes da obra são muito importantes, pois algumas interferências podem inviabilizar o projeto.

Por fim, o Laudo Técnico elaborado passou a compor a documentação do processo judicial, que, após publicada a sentença, foi permitida a retomada da obra de reforma do imóvel. Vê-se, portanto, que a atividade de inspeção, a avaliação e análise das condições de uma edificação, a emissão das recomendações sobre a terapia corretiva sugerida e apresentada no laudo, contribuiram para a solução dos problemas que causaram a ação judicial. 


\section{REFERÊNCIAS}

Associação Brasileira de Normas Técnicas. (2014). NBR 6118: Projeto de estruturas de concreto - Procedimento. Rio de Janeiro.

Associação Brasileira de Normas Técnicas. (2019). NBR 6122: Projeto e execução de fundações. Rio de Janeiro.

Associação Brasileira de Normas Técnicas. (2020). NBR 16.747: Inspeção predial - Diretrizes, conceitos, terminologia e procedimentos. Rio de Janeiro.

Campani, P.B. (2011). “Análise comparativa entre lajes nervuradas simples e duplas por analogia de grelha" Trabalho de Conclusão de Graduação - Universidade Fedral do Rio Grande do Sul, p. 30 .

Cavallazz M.A.L. (2016). "Laudo de Inspeção Predial - Centro Comercial Di Bernardi Tower” Empresa Pravaliar Engenharia Civil e de Segurança do Trabalho.

Chaves, G. V. de A. (2012), “Avaliação do papel da faixa de domínio na redução de vibrações produzidas por trens em áreas urbanas.” Dissertação de Mestrado - Universidade Fedral da Paraíba, p. 37

Instituto Brasileiro de Avaliações e Perícias de Engenharia. (2015). Norma Básica para Perícias de Engenharia. São Paulo.

Instituto Brasileiro de Avaliações e Perícias de Engenharia. (2012). Norma de Inspeção Predial Nacional. São Paulo.

Thomaz, Ercio. (2020). “Trincas em Edificios: Causas, Prevenção e Recuperação”. Oficina de Textos, São Paulo, p. 